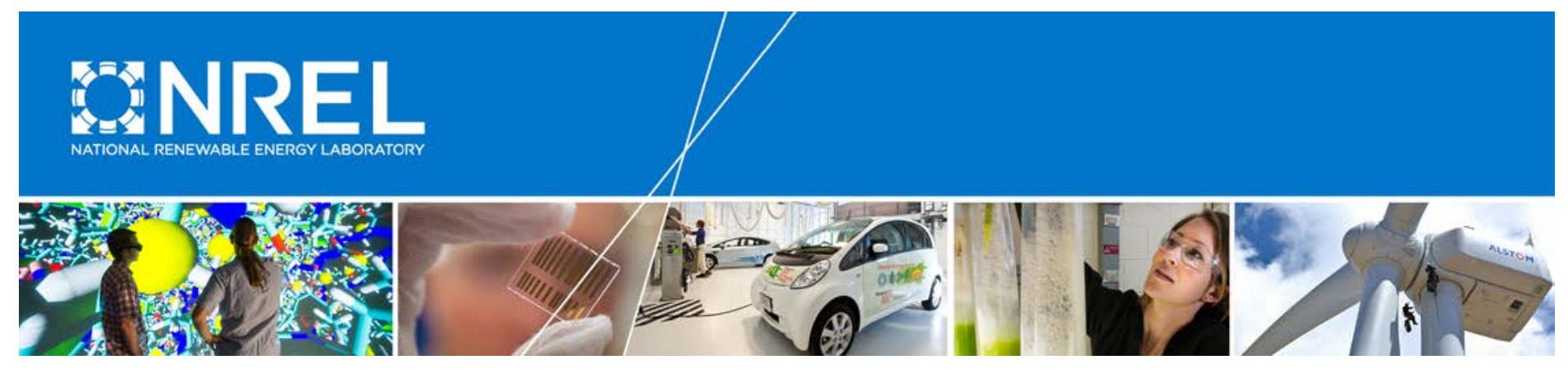

\title{
Coupled Mooring Analyses for the WEC-Sim Wave Energy Converter Design Tool
}

\section{Preprint}

Senu Sirnivas and Yi-Hsiang Yu

National Renewable Energy Laboratory

Matthew Hall

University of Maine

Bret Bosma

Oregon State University

Presented at the $35^{\text {th }}$ International Conference on Ocean, Offshore and Arctic Engineering (OMAE 2016)

Busan, South Korea

June 19-24, 2016

NREL is a national laboratory of the U.S. Department of Energy Office of Energy Efficiency \& Renewable Energy Operated by the Alliance for Sustainable Energy, LLC

This report is available at no cost from the National Renewable Energy Laboratory (NREL) at www.nrel.gov/publications.

Conference Paper

NREL/CP-5000-65918

July 2016

Contract No. DE-AC36-08GO28308 


\section{NOTICE}

The submitted manuscript has been offered by an employee of the Alliance for Sustainable Energy, LLC (Alliance), a contractor of the US Government under Contract No. DE-AC36-08GO28308. Accordingly, the US Government and Alliance retain a nonexclusive royalty-free license to publish or reproduce the published form of this contribution, or allow others to do so, for US Government purposes.

This report was prepared as an account of work sponsored by an agency of the United States government. Neither the United States government nor any agency thereof, nor any of their employees, makes any warranty, express or implied, or assumes any legal liability or responsibility for the accuracy, completeness, or usefulness of any information, apparatus, product, or process disclosed, or represents that its use would not infringe privately owned rights. Reference herein to any specific commercial product, process, or service by trade name, trademark, manufacturer, or otherwise does not necessarily constitute or imply its endorsement, recommendation, or favoring by the United States government or any agency thereof. The views and opinions of authors expressed herein do not necessarily state or reflect those of the United States government or any agency thereof.

This report is available at no cost from the National Renewable Energy Laboratory (NREL) at www.nrel.gov/publications.

Available electronically at SciTech Connect http:/www.osti.gov/scitech

Available for a processing fee to U.S. Department of Energy and its contractors, in paper, from:

U.S. Department of Energy

Office of Scientific and Technical Information

P.O. Box 62

Oak Ridge, TN 37831-0062

OSTI http://www.osti.gov

Phone: 865.576.8401

Fax: 865.576.5728

Email: reports@osti.gov

Available for sale to the public, in paper, from:

U.S. Department of Commerce

National Technical Information Service

5301 Shawnee Road

Alexandria, VA 22312

NTIS http://www.ntis.gov

Phone: 800.553 .6847 or 703.605 .6000

Fax: 703.605.6900

Email: orders@ntis.gov 


\section{COUPLED MOORING ANALYSES FOR THE WEC-SIM WAVE ENERGY CONVERTER DESIGN TOOL}

\author{
Senu Sirnivas \\ National Renewable Energy Laboratory \\ Golden, CO, USA \\ Email: senu.sirnivas@nrel.gov \\ Matthew Hall \\ The University of Maine \\ Orono, Maine, USA \\ Email: matthew.hall1@maine.edu
}

\author{
Yi-Hsiang Yu* \\ National Renewable Energy Laboratory \\ Golden, CO, USA \\ Email: yi-hsiang.yu@nrel.gov \\ Bret Bosma \\ Oregon State University \\ Corvallis, Oregon, USA \\ Email: bosma@eecs.oregonstate.edu
}

\begin{abstract}
A wave-energy-converter-specific time-domain modeling method (WEC-Sim) was coupled with a lumped-mass-based mooring model (MoorDyn) to improve its mooring dynamics modeling capability. This paper presents a verification and validation study on the coupled numerical method. First, a coupled model was built to simulate a $1 / 25$ model scale floating power system connected to a traditional three-point catenary mooring with an angle of 120 between the lines. The body response and the tension force on the mooring lines at the fairlead in decay tests and under regular and irregular waves were examined. To validate and verify the coupled numerical method, the simulation results were compared to the measurements from a wave tank test and a commercial code (OrcaFlex). Second, a coupled model was built to simulate a two-body point absorber system with a chain-connected catenary system. The influence of the mooring connection on the point absorber was investigated. Overall, the study showed that the coupling of WEC-Sim and the MoorDyn model works reasonably well for simulating a floating system with practical mooring designs and predicting the corresponding dynamic loads on the mooring lines. Further analyses on improving coupling efficiency and the feasibility of applying the numerical method to simulate WEC systems with more complex mooring configuration are still needed.
\end{abstract}

\footnotetext{
*Address all correspondence to this author.
}

\section{KEYWORDS}

Wave energy; mooring dynamics analysis; time-domain numerical model; radiation and diffraction theory; lumped-mass model

\section{INTRODUCTION}

The mooring system is an essential part of the overall design for a floating wave energy converter (WEC). It is often applied to keep the device in position and needs to be designed to sustain the wave-induced loads under harsh wave environments. A poor mooring design may not only result in system failure but reduce the efficiency of the device to generate power; however, the design of mooring for WEC systems can be challenging because of the nonlinear hydrodynamic phenomena during the survival seas and the fatigue forces under operational wave environments [1]. Therefore, the development of the mooring capability for WEC modeling tools is essential when performing system design analyses.

A time-domain wave-to-wire numerical model, the Wave Energy Converter Simulator (WEC-Sim) [2,3], was developed for modeling WEC devices. The model is an open-source numerical tool that uses the MATLAB SimMechanics package to calculate multibody dynamics and computes wave interactions using the hydrodynamic coefficients derived from frequency-domain boundary-element methods. WEC-Sim can model these devices, which are comprised of rigid bodies, power take-off systems, and simple mooring systems using user-specified mooring stiff- 
ness and damping matrices. To model realistic mooring designs for floating WECs, WEC-Sim was coupled with a lumped-massbased mooring model, MoorDyn [4]. MoorDyn accounts for the submerged weight, inertia, and axial elasticity of each mooring line, as well as hydrodynamic added mass, drag forces, and vertical spring-damper forces from contact with the seabed. It has been successfully validated with semisubmersible offshore wind platform model test data [5].

This paper presents a verification and validation study on the coupled WEC-Sim/MoorDyn model. First, we describe the application of a coupled numerical model to simulate a 1/25model-scale floating buoy. The buoy was connected to a traditional three-point catenary mooring system with an angle of 120 between the lines. To verify and validate our numerical model, the simulation results were compared to the measurements from a wave tank test [6] and the results from a commercial offshore dynamic analysis and marine system modeling tool (OrcaFlex [7]). The buoy response and the tension force on the mooring lines in decay tests and under both regular and irregular waves were examined. Second, we present the application of the WEC-Sim/MoorDyn model for simulating a two-body point absorber system to demonstrate its capability for modeling a practical chain-connected WEC design. Finally, we provide a discussion on model performance and further applications.

\section{METHODOLOGY}

This section describes the numerical models used in WECSim and MoorDyn as well as the algorithm for coupling the two numerical methods.

\section{WEC-Sim}

WEC-Sim is a time-domain numerical model for solving the system dynamics of multibody WECs using the radiation and diffraction method and a simple power take-off (PTO) model Yu2014,Ruehl2014. Figure 1 shows hydrodynamic blocks in WEC-Sim and the WEC model setup. The dynamic response in WEC-Sim is calculated by solving the equation of motion for each body about its center of gravity. Based on Cummins' equation [8], the equation of motion can be written as:

$$
\begin{aligned}
\left(m+A_{\infty}\right) \ddot{X}= & -\int_{0}^{t} K(t-\tau) \dot{X}(\tau) d \tau \\
& +F_{\text {ext }}+F_{\text {vis }}+F_{\text {res }}+F_{P T O}+F_{\text {moor }}
\end{aligned}
$$

where $A_{\infty}$ is the added mass matrix at infinite frequency, $X$ is the (translational and rotational) displacement vector of the body, $m$ is the mass matrix, $K$ is the impulse response function, $F_{\text {ext }}$ is the wave excitation force, $F_{P T O}$ is the force from the PTO system, $F_{\text {moor }}$ is the force from the mooring connection, $F_{v i s}$ is the quadratic viscous damping term, and $F_{\text {res }}$ is the net buoyancy restoring force. In this study, all the hydrodynamic coefficients,

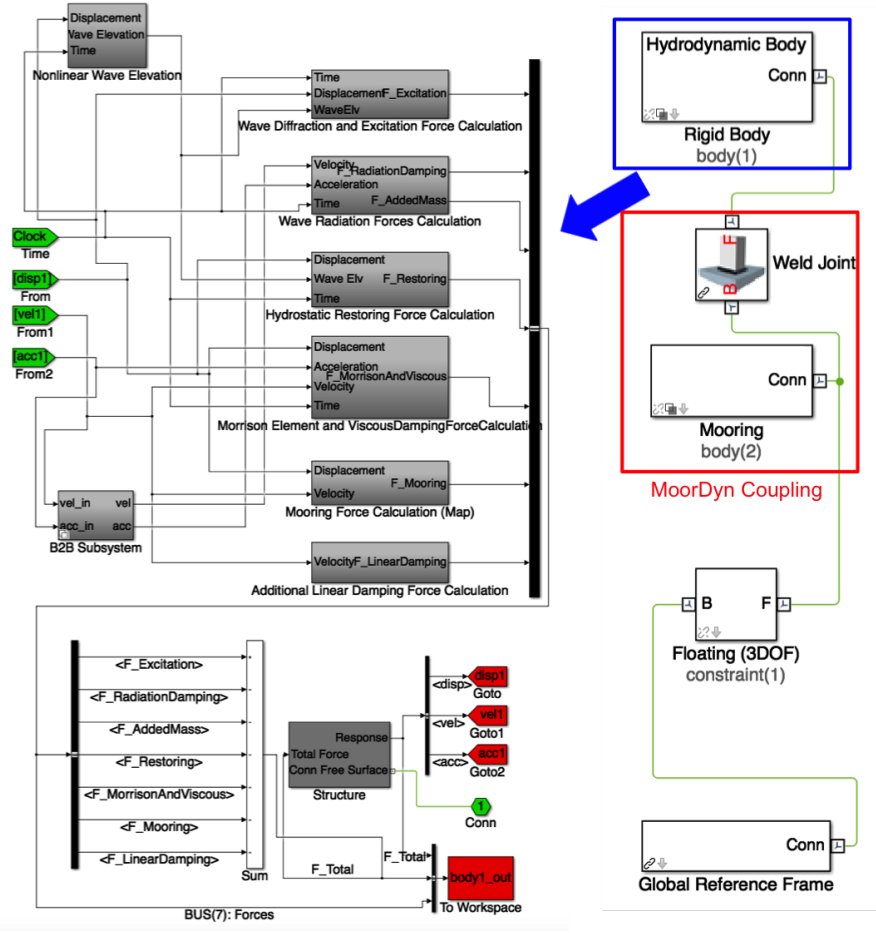

FIGURE 1. WEC-SIM HYDRODYNAMIC BLOCKS AND THE WEC MODEL COUPLED WITH MOORDYN.

including the added mass, wave excitation, impulse response function, and the restoring stiffness terms were obtained from WAMIT [9], which is a frequency-domain potential flow solver developed using the boundary element method. The mooring force was computed from MoorDyn at each time step.

\section{MoorDyn}

MoorDyn is an open-source, lumped-mass mooring dynamics model. It discretizes each line in a mooring system into evenly sized line segments connected by node points (Fig. 2). The line mass is lumped at these node points, along with gravitational and buoyancy forces, hydrodynamic loads, and reactions from contact with the seabed. Hydrodynamic drag and added mass are calculated based on Morison's equation. A mooring line's axial stiffness is modeled by applying a linear stiffness to each line segment, in tension only. A damping term is also applied in each segment to dampen nonphysical resonances caused by the lumped-mass discretization. Bending and torsional stiffnesses are neglected. Bottom contact is represented by vertical stiffness and damping forces when nodes pass below the seabed [5].

MoorDyn typically operates at a smaller time step than floating platform models. Therefore, it handles its own time integration, solving each node's equations of motion with a secondorder Runge-Kutta integrator. This modeling approach was successfully validated for $1 / 50$-scale floating wind turbine test data [5]. Further details about the formulation are available in this reference. MoorDyn also allows modeling of interconnections 


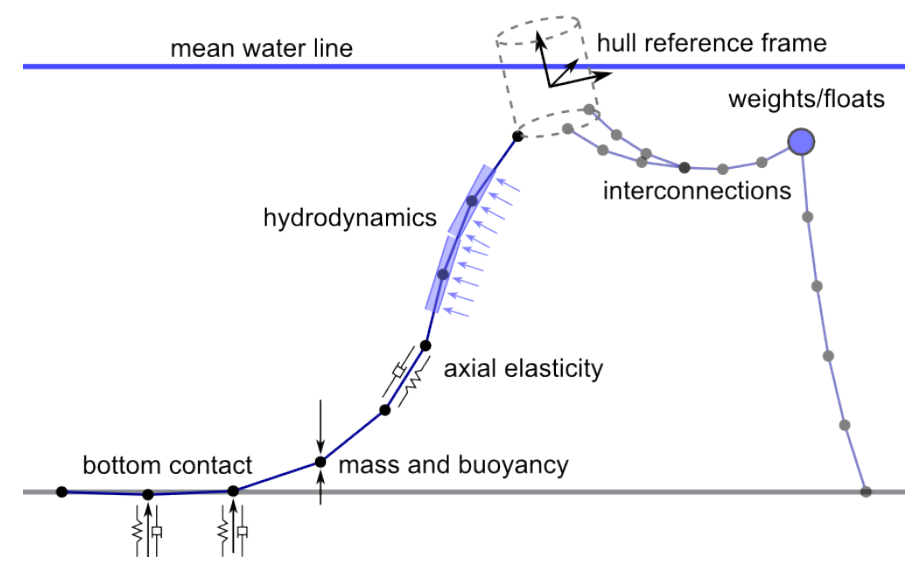

FIGURE 2. MOORDYN MOORING MODEL ELEMENTS.

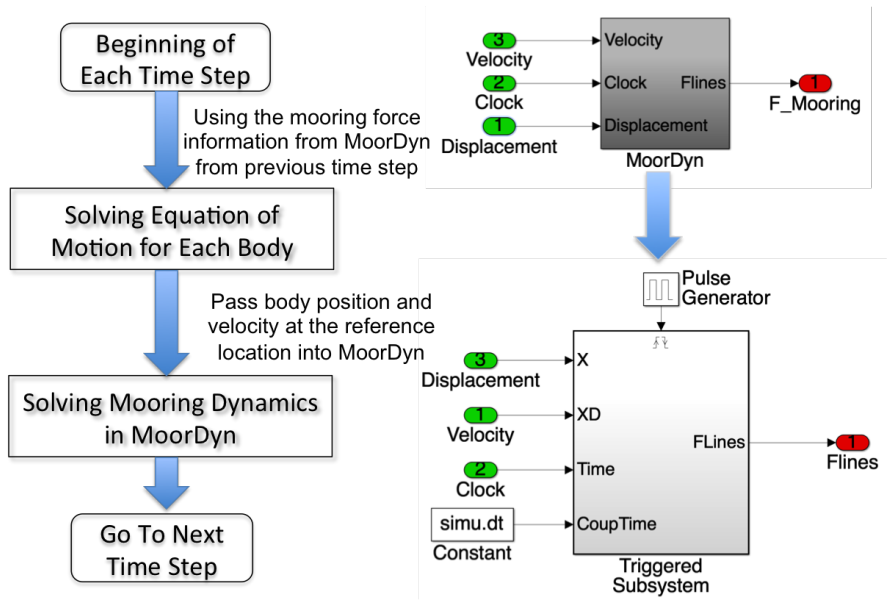

FIGURE 3. THE FLOWCHART AND MOORDYN COUPLING BLOCKS IN WEC-SIM.

between lines, and weight or buoyancy elements at the connections. Some demonstration of these capabilities has been done for model-scale tests of a pitching WEC [10].

\section{WEC-Sim/MoorDyn Coupling}

WEC-Sim is coupled with MoorDyn using a loose-coupling approach, similar to that of [10]. The two methods exchange the forces and response information at a specified reference point, which is defined in the global reference frame coordinate system but moves with the floating body. Figure 3 shows the flowchart for the WEC-Sim and MoorDyn coupling procedure and the Simulink blocks used in the WEC-Sim model (inside the mooring block in Fig. 1). At each time step, the model first solves the system dynamics for each body (Eqn. 1) by using the mooring force vector calculated in MoorDyn from the previous time step. After the body response is calculated, MoorDyn uses the displacement and velocity information to update the mooring force. Note that the loose coupling approach generally requires a small time step in the coupled WEC-Sim simulations to keep the solution stable.

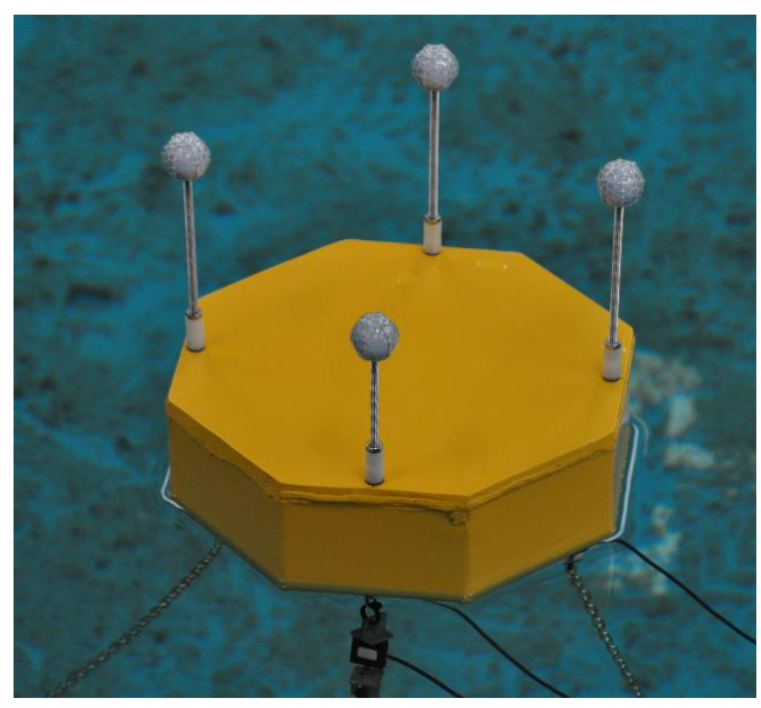

FIGURE 4. FPS MODEL USED IN THE BEAUFORT RESEARCH WAVE BASIN TANK TEST [6].

\section{VERIFICATION AND VALIDATION STUDY}

This section presents a verification and validation study on the coupled WEC-Sim/MoorDyn model. The coupled simulation results were compared to those obtained from OrcaFlex and the measurement data from an experimental wave tank test.

\section{Model Geometry and Mooring Configuration}

The experimental test data used for validation are from a study on the performance assessment of a floating power system (FPS) [6]. The test was carried out at the Beaufort Research Wave Basin in Ireland (Fig. 4). The 1/25 FPS scale model was built using a thermoplastic polycarbonate material. The FPS has a diameter of $200 \mathrm{~mm}$, an overall height of $90 \mathrm{~mm}$, and a draft of $30 \mathrm{~mm}$. The center of gravity is located approximately $29 \mathrm{~mm}$ above the water line, and the mass of the FPS is $766.4 \mathrm{~g}$ without the mooring lines attached.

Figures 5 and 6 show the scaled FPS in the wave basin and the mooring configuration from the top, respectively. The FPS has a traditional three-point catenary mooring system. The mooring line length is $3 \mathrm{~m}$ and the angle between the lines is 120 . The FPS mooring chain has a linear density value of $45.5 \mathrm{~g} / \mathrm{m}$. The anchor points are placed $2.6 \mathrm{~m}$ from the body center in plane.

\section{Numerical Model Setup}

The numerical simulations were setup in the model scale to perform a one-to-one comparison with the model test results. Figure 6 also shows the mooring tension at the neutral position for the model test (MT), OrcaFlex (OF), and WEC-Sim (WS). The mooring configuration for the simulation was adjusted to match the tension of the model test as close as possible. In the OrcaFlex simulations, the model was set up with a time step size of $0.01 \mathrm{~s}$ and 12 segments on each mooring line. Morison's element model was applied with drag coefficients of 0.75 and 1.1 in 


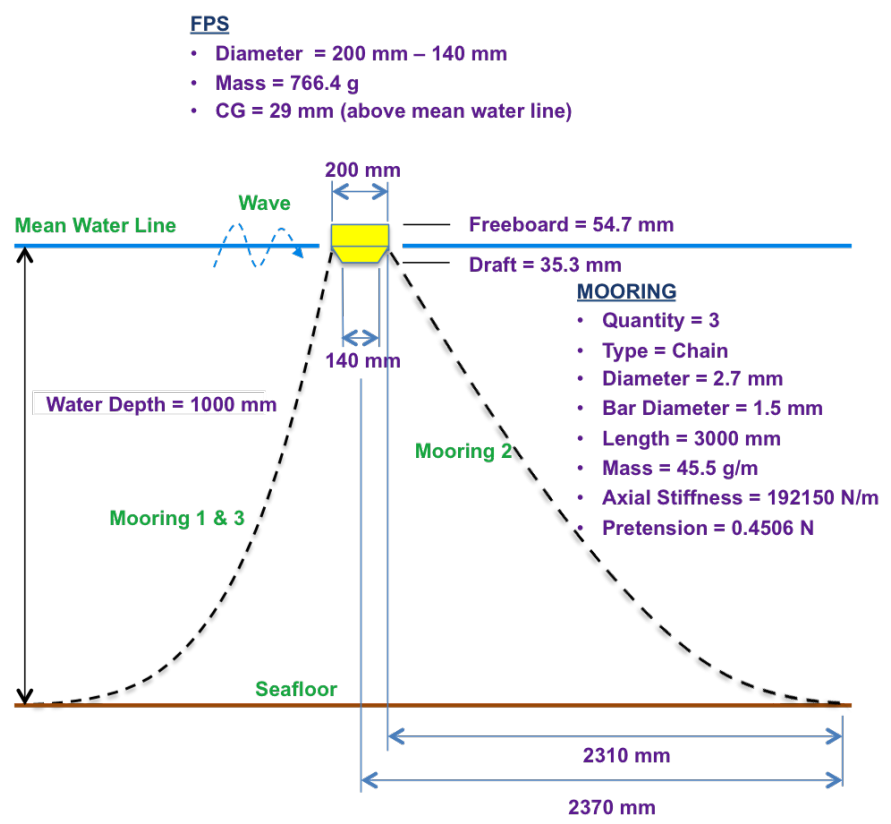

FIGURE 5. FPS MOORING CONFIGURATION.

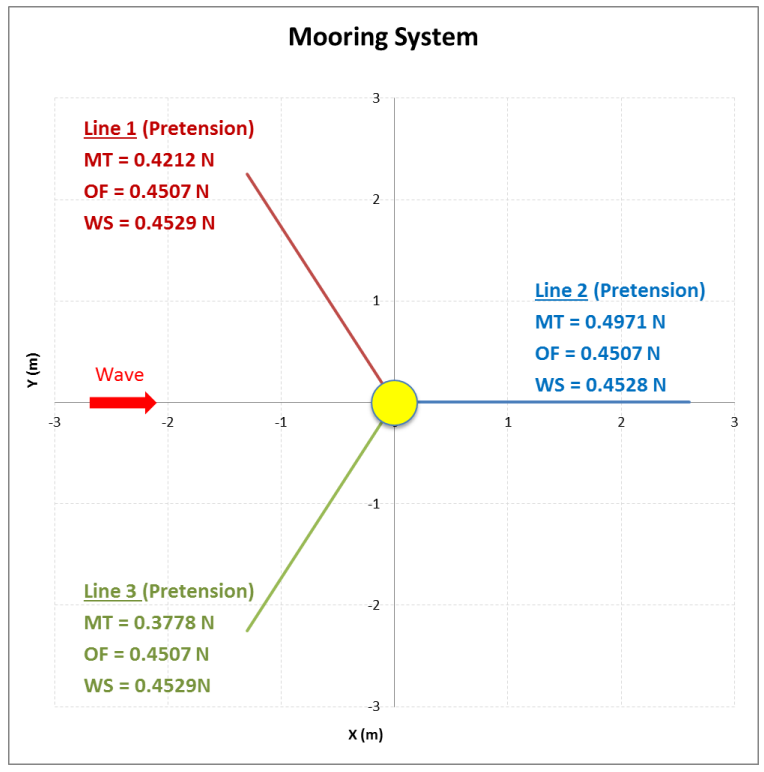

FIGURE 6. FPS MODEL TEST MOORING LAYOUT.

the normal and vertical directions, respectively. The drag coefficients applied are generic values typical for these systems, and in reality could be slightly different and would not change the conclusion of the coupling approach. In the WEC-Sim simulations, the drag coefficient was specified in each degree of freedom, where 0.75 and 1.1 were given in surge and heave directions, respectively. The drag value in pitch was adjusted by matching the pitch decay response obtained from the OrcaFlex simulation in the case without mooring connection (Fig. 7). By using a loosecoupling algorithm, we applied a small time step of $10^{-4} \mathrm{~s}$ in the

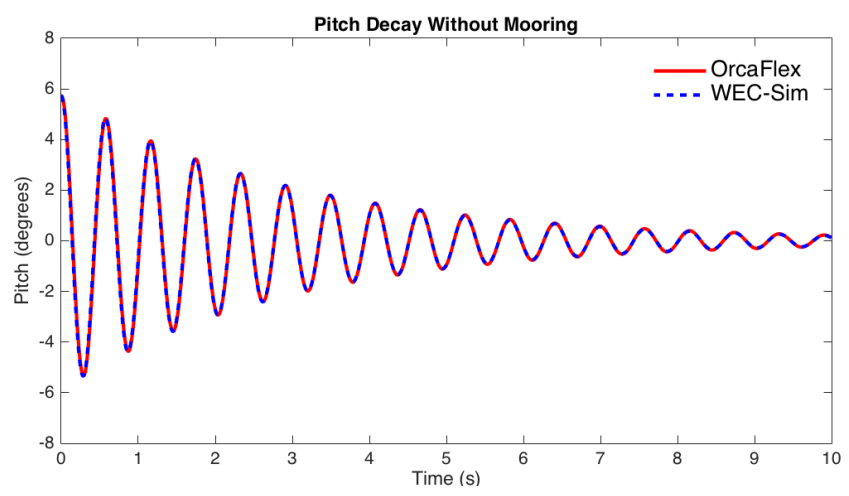

FIGURE 7. PITCH DECAY TIME HISTORY WITHOUT MOORING CONNECTION.

WEC-Sim/MoorDyn model. For each mooring line, 24 segments were used based on a segment sensitivity study in the decay test to ensure that the solutions were converged.

\section{Decay Tests}

To verify the WEC-Sim/MoorDyn coupling model, heave and surge decay tests were performed. Figure 8 shows the comparison of the response and mooring tension histories in the heave decay test obtained from WEC-Sim and OrcaFlex. The test was carried out by starting the FPS at the initial position, where the hydrodynamic coefficients were calculated in WAMIT. Because of the additional weight from the mooring lines, the body sank $5.3 \mathrm{~mm}$ before it reached the system equilibrium position.
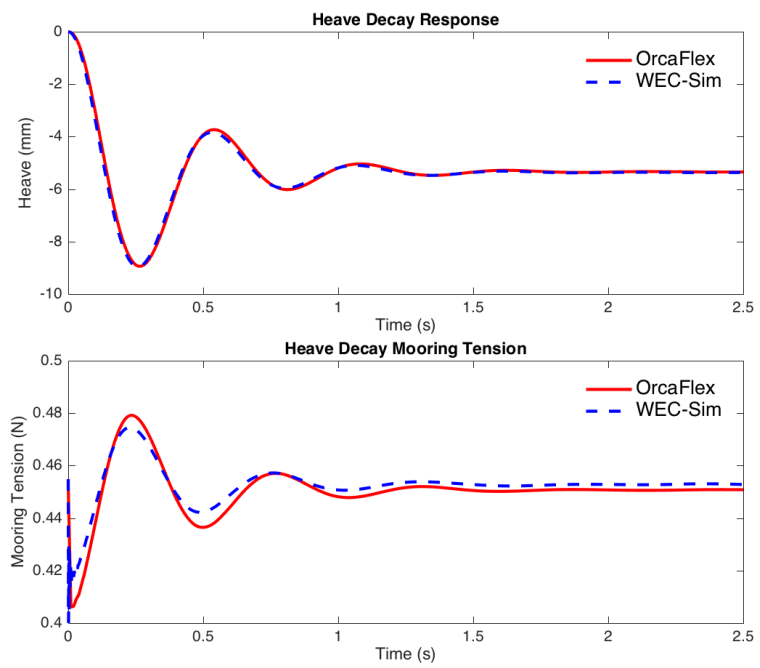

FIGURE 8. FPS HEAVE DECAY TEST RESPONSE (TOP) AND MOORING FORCE HISTORY (BOTTOM).

The surge decay test was performed by specifying an initial displacement of $100 \mathrm{~mm}$ in surge and an initial angle of $0.1 \mathrm{rad}$. Figure 9 shows the response from heave, surge, and pitch and the 

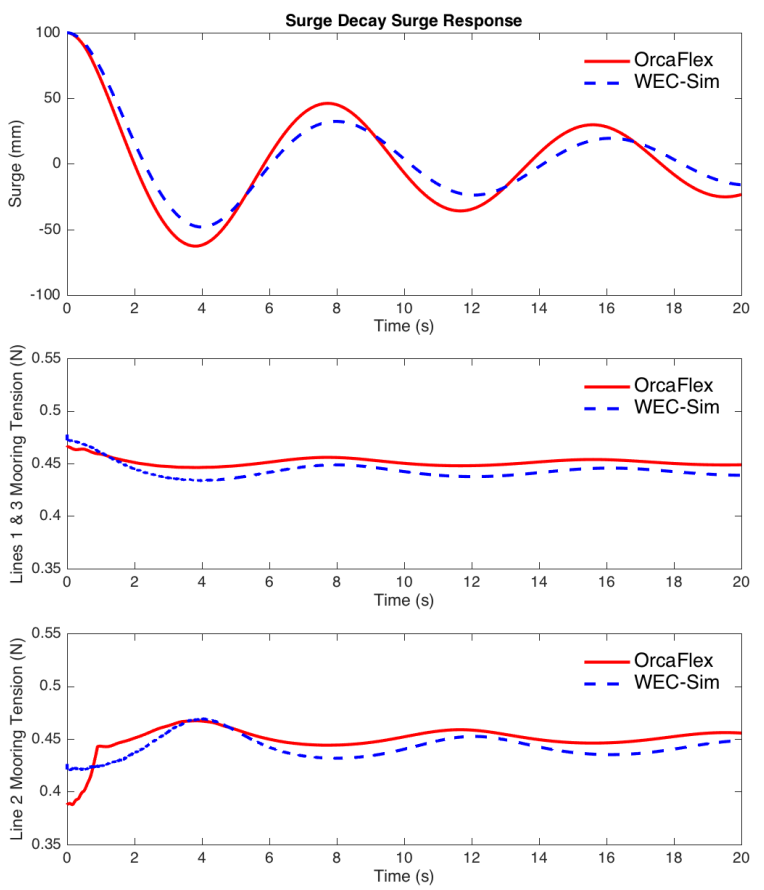

FIGURE 9. FPS HEAVE DECAY TEST RESPONSE (TOP) AND MOORING FORCE HISTORY FOR LINE 1 (BOTTOM).

mooring tension for the first mooring line in the surge decay test. Overall, WEC-Sim and OrcaFlex agreed reasonably well in both decay tests; however, the WEC-Sim/MoorDyn coupling model requires a higher resolution in space (i.e., number of segments per mooring line) and a smaller time step to obtain a converged solution.

\section{Regular Wave Results}

The simulations in OrcaFlex and WEC-Sim were performed using a regular wave with a wave height of $40 \mathrm{~mm}$ and a period of $0.8 \mathrm{~s}$. The total simulation time was $28 \mathrm{~s}$, with $8 \mathrm{~s}$ of ramp time and $20 \mathrm{~s}$ of actual data for comparison. The results are within reason, given the difference in mooring pretension and the numerical algorithm used in the mooring model. Figure 10 shows the comparison between the model test, OrcaFlex, and WEC-Sim for surge, heave, and pitch. The WEC-Sim/MoorDyn simulations slightly underpredict the surge, with OrcaFlex being closer to the model test. The heave and pitch response has a decent match to the model test. WEC-Sim/MoorDyn used 24 segments per mooring line, and OrcaFlex only used 12 segments, which could lead to the slight overprediction for pitch.

Figure 11 shows the comparison of mooring loads at the fairlead between the measurements from the model test and the simulation results from OrcaFlex and WEC-Sim/MoorDyn. The mooring line loads are similar between OrcaFlex and WEC-Sim, but the amplitude is smaller compared to the model test. The slight difference in amplitude and shift of mean mooring force between the wave tank test measurements and the simulation results were most likely caused by the imbalance of mooring con-
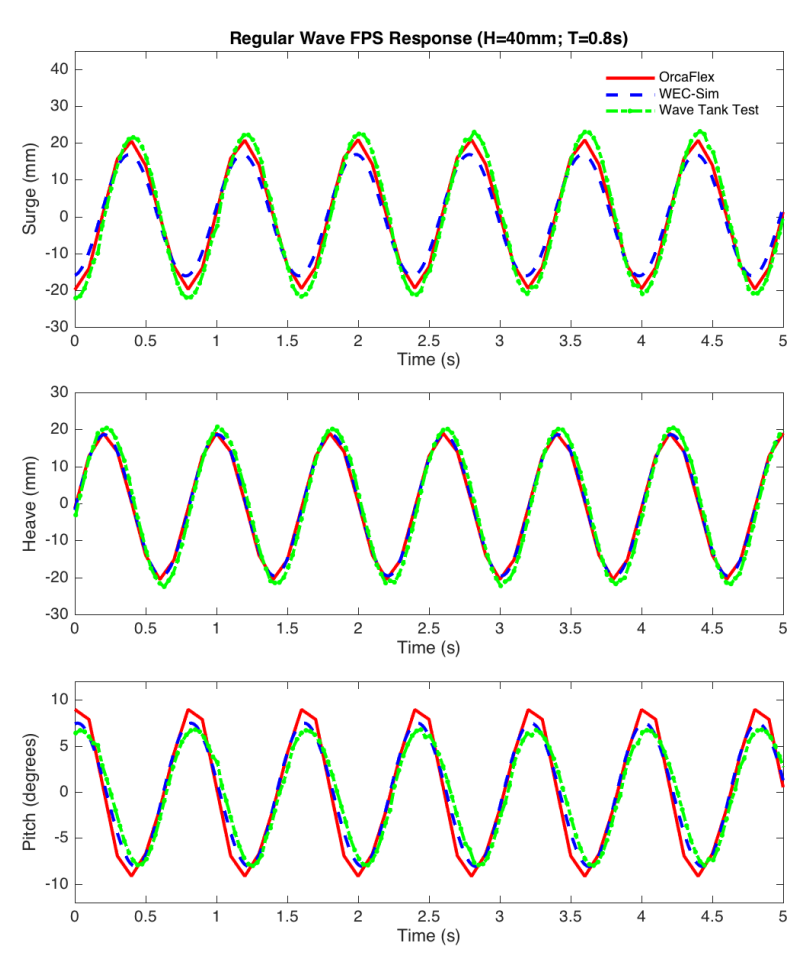

FIGURE 10. MOTION RESPONSE IN SURGE, HEAVE, AND PITCH FROM WEC-SIM, ORCAFLEX, AND THE WAVE TANK TEST MEASUREMENTS.
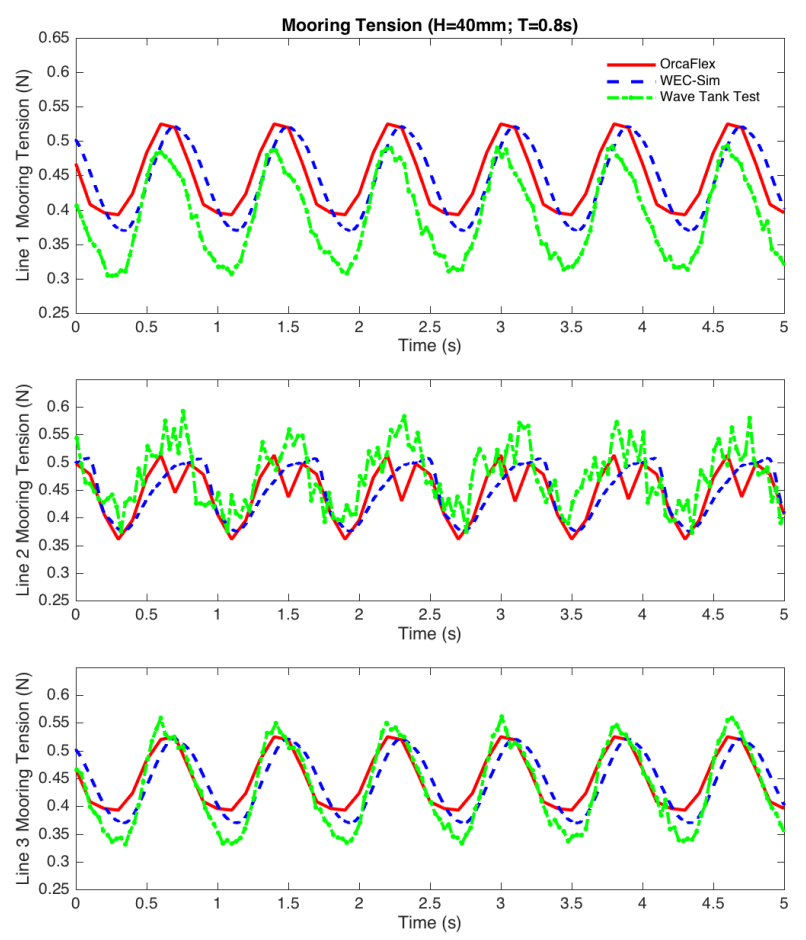

FIGURE 11. MOORING FORCE IN THE X, Y, AND Z DIRECTIONS FROM WEC-SIM, ORCAFLEX, AND THE WAVE TANK TEST MEASUREMENTS. 
TABLE 1. STATISTICS OF THE FPS MOORING LOAD FOR THE REGULAR WAVE CASE.

\begin{tabular}{ll|lll}
\hline & & M1 [N] & M2 [N] & M3 [N] \\
\hline \multirow{4}{*}{ Mean } & MT & 0.390 & 0.476 & 0.435 \\
& OF & 0.450 & 0.446 & 0.450 \\
& WS & 0.446 & 0.448 & 0.446 \\
\hline \multirow{3}{*}{$\begin{array}{l}\text { Standard } \\
\text { Deviation }\end{array}$} & MT & 0.061 & 0.054 & 0.073 \\
& OF & 0.051 & 0.051 & 0.051 \\
& WS & 0.052 & 0.046 & 0.052 \\
\hline
\end{tabular}

MT: model test; OF: OrcaFlex; WS: WEC-Sim

M1: Line 1; M2: Line 2; M3: Line 3

nection, as shown in Fig. 6. As mentioned earlier, the simulation mooring configuration was adjusted to try to match the model test pretension because the original model test mooring length and anchor location resulted in higher pretension in the simulation models. Note that the pretension on lines 1 and 3 are lower and higher on line 2 for the model test compared to the simulation-predicted pretensions. The consequence of this adjustment is reflected in the results. The mooring load statistics of the simulation are listed in Tab. 1, where both OrcaFlex and the WEC-Sim/MoorDyn model show very similar predictions.

\section{Irregular Wave Results}

The irregular wave simulations in OrcaFlex and WEC-Sim were performed using a JONSWAP spectrum with a significant wave height of $20 \mathrm{~mm}$ and a peak period of $1.2 \mathrm{~s}$. The simulation time was $370 \mathrm{~s}$, with a 10-s ramp time for the transient. The simulation time step was $10^{-4} \mathrm{~s}$; however, the convolution integral was integrated every 10 time steps to save time.

The surge, heave, and pitch motion comparisons between OrcaFlex and WEC-Sim are shown in Fig. 12. The heave response matches extremely well, the surge response differs sightly, and the pitch response is slightly overpredicted by OrcaFlex. These responses could be attributed to the difference in the mooring model between OrcaFlex, which had 12 members, and WEC-Sim, which had 15 members.

Similar differences to pitch response are seen in the comparison of the mooring line fairlead forces shown in Fig. 13. The mooring load statistics of the simulation are listed in Tab. 2, where both the OrcaFlex and WEC-Sim/MoorDyn models show very similar results with a slightly higher standard deviation in OrcaFlex. Again, the difference between the number of members between the two models are the probable cause.

The comparison between OrcaFlex and WEC-Sim for the spectral density in surge, heave, pitch, and the mooring loads on all three mooring lines at the fairlead are shown in Fig. 14. The simulation results from the two models agree well for most of the range of the frequency, except for the longer wave frequency
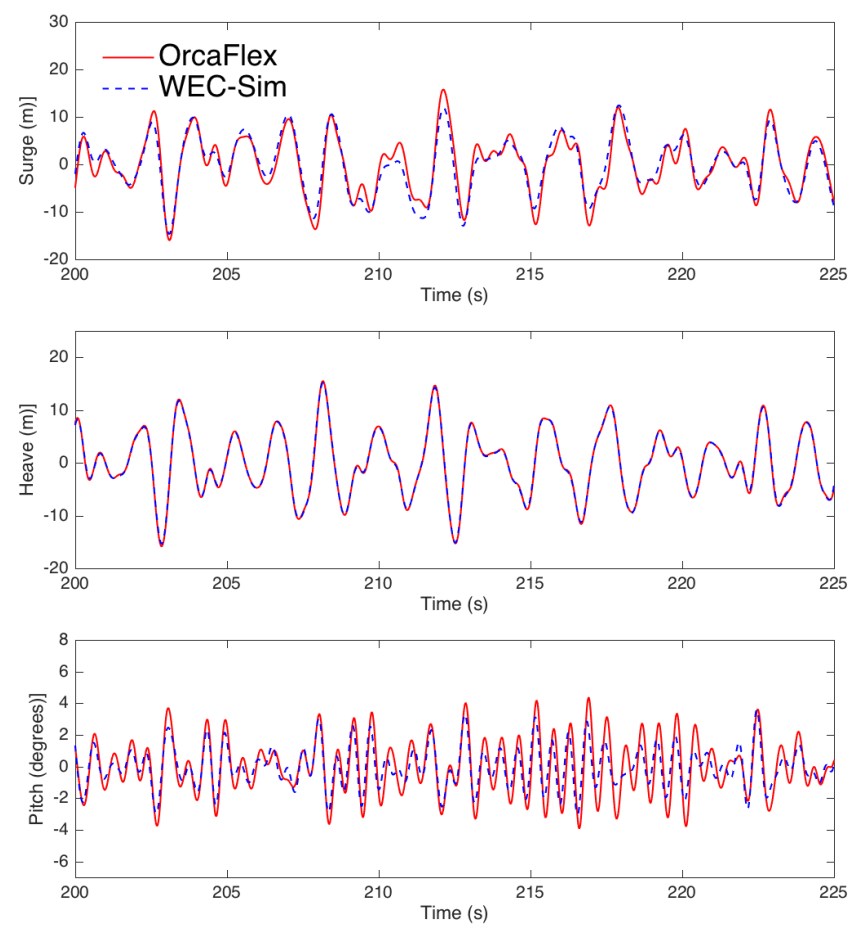

FIGURE 12. WEC-SIM AND ORCAFLEX MOTION RESPONSE COMPARISON IN SURGE, HEAVE, AND PITCH.
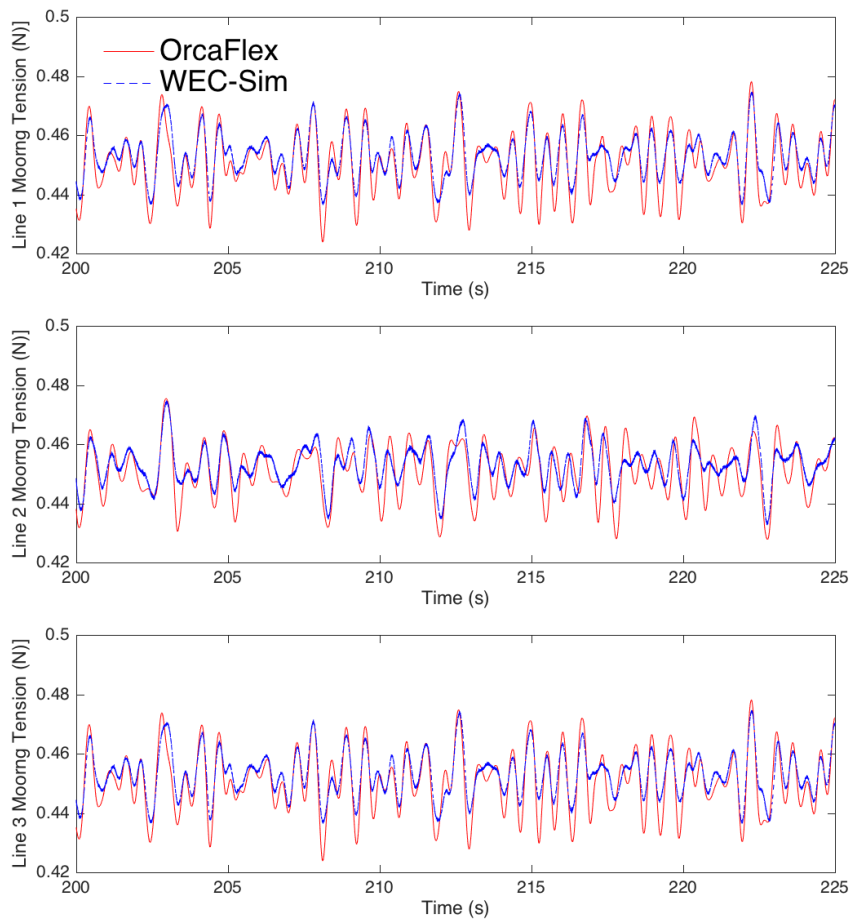

FIGURE 13. WEC-SIM AND ORCAFLEX MOORING FORCE COMPARISONS IN X, Y, AND Z DIRECTIONS. 
TABLE 2. STATISTICS OF THE FPS MOORING LOAD FOR THE IRREGULAR WAVE CASE.

\begin{tabular}{ll|lll}
\hline & & M1 [N] & M2 [N] & M3 [N] \\
\hline \multirow{2}{*}{ Mean } & OF & 0.451 & 0.451 & 0.451 \\
& WS & 0.453 & 0.453 & 0.453 \\
\hline Standard & OF & 0.009 & 0.008 & 0.009 \\
Deviation & WS & 0.007 & 0.006 & 0.007 \\
\hline
\end{tabular}
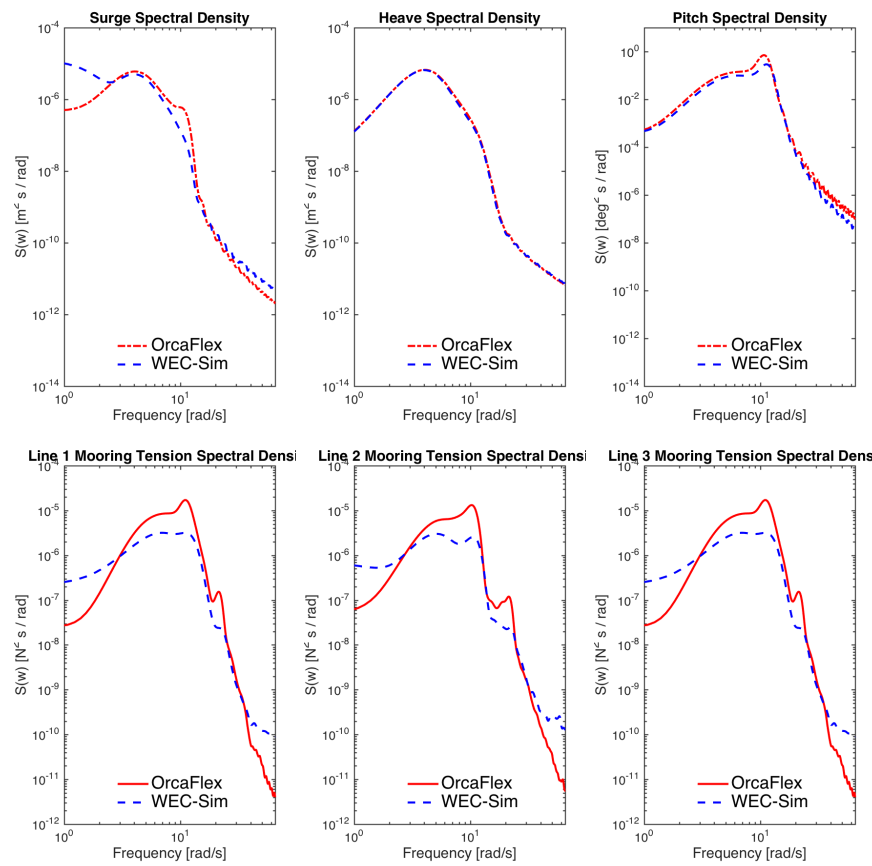

FIGURE 14. THE SPECTRAL DENSITY FOR SURGE, HEAVE, PITCH, AND THE FAIRLEAD MOORING LOADS.

range.

\section{APPLICATION FOR A TWO-BODY POINT ABSORBER}

An application of a coupled WEC-Sim/MoorDyn model for simulating a floating two-body point absorber WEC design is presented in this section.

\section{Model Properties and Mooring Setup}

The simulated model was based on the one developed in the U.S. Department of Energy's Reference Model Project [3, 11]. It contains a float and a spar/plate that is connected to a central column, and it converts energy from the relative motion between the float and the spar/plate induced by ocean waves. The relative motion is in the axial direction of the device and is predominantly in heave (vertical direction). The dimensions and mass properties for the floating point absorber (FPA) design are presented in Fig. 15 and Tab. 3. The mass properties included the mass of the

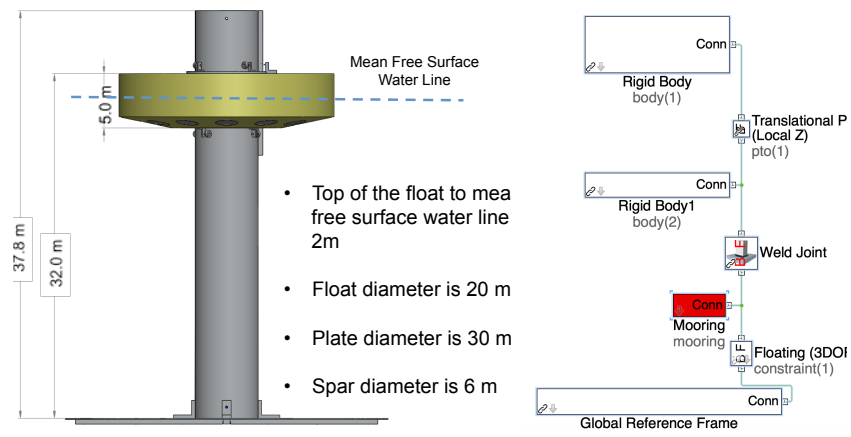

FIGURE 15. THE SCHEMATIC OF THE FPA CONCEPT DESIGN (LEFT) AND THE WEC-SIM MODEL (RIGHT).

TABLE 3. MASS PROPERTIES FOR THE TWO-BODY FPA.

\begin{tabular}{llllll}
\hline & $\begin{array}{l}\text { Center of } \\
\text { Gravity (m) }\end{array}$ & $\begin{array}{l}\text { Mass } \\
(\text { Ton })\end{array}$ & \multicolumn{3}{c}{$\begin{array}{c}\text { Moment of Inertia } \\
\left(\text { Ton- }{ }^{2}\right)\end{array}$} \\
\hline \multirow{3}{*}{ Float } & & & 20900 & 0 & 0 \\
& {$[0,0,-0.72]$} & 727.01 & 0 & 21300 & 4.3 \\
& & & 0 & 4.3 & 37100 \\
\hline \multirow{3}{*}{$\begin{array}{l}\text { Spar } \\
\text { Plate }\end{array}$} & {$[0,0,-21.29]$} & 878.3 & 0 & 137000 & 218 \\
& & & 0 & 218 & 28500 \\
\hline
\end{tabular}

device and ballast. We assumed both the float and the spar/plate were located at their equilibrium positions, in which the mass for each body was equal to its displaced mass.

The mooring configuration for the two-body point absorber system is similar to the one used for the FPS verification and validation study, in which the spar/plate was connected to a traditional three-point catenary mooring system with an angle of $120^{\circ}$. The mooring chain length is $280 \mathrm{~m}$ and has a diameter of $0.144 \mathrm{~m}$ and a linear density value of $126 \mathrm{~g} / \mathrm{m}$. The fairlead is $10 \mathrm{~m}$ below the mean water surface, and the anchor points are located $267 \mathrm{~m}$ from the body center in plane.

\section{Simulation Results}

The simulation was conducted using a 400-s time series (measured in 2008) from the National Data Buoy Center buoy \#46229 located off the coast of Oregon (Fig. 16). The PTO system was represented using a linear spring-damper with a PTO damping coefficient of $1200 \mathrm{kN} / \mathrm{m}$. The hydrodynamic coefficients were also obtained from WAMIT, with more modeling described in the studies of $[2,3]$.

The device's response time history in surge and pitch as well as the relative motion between the float and the spar/plate are presented in Fig. 16. For comparison purposes, a no-mooring 

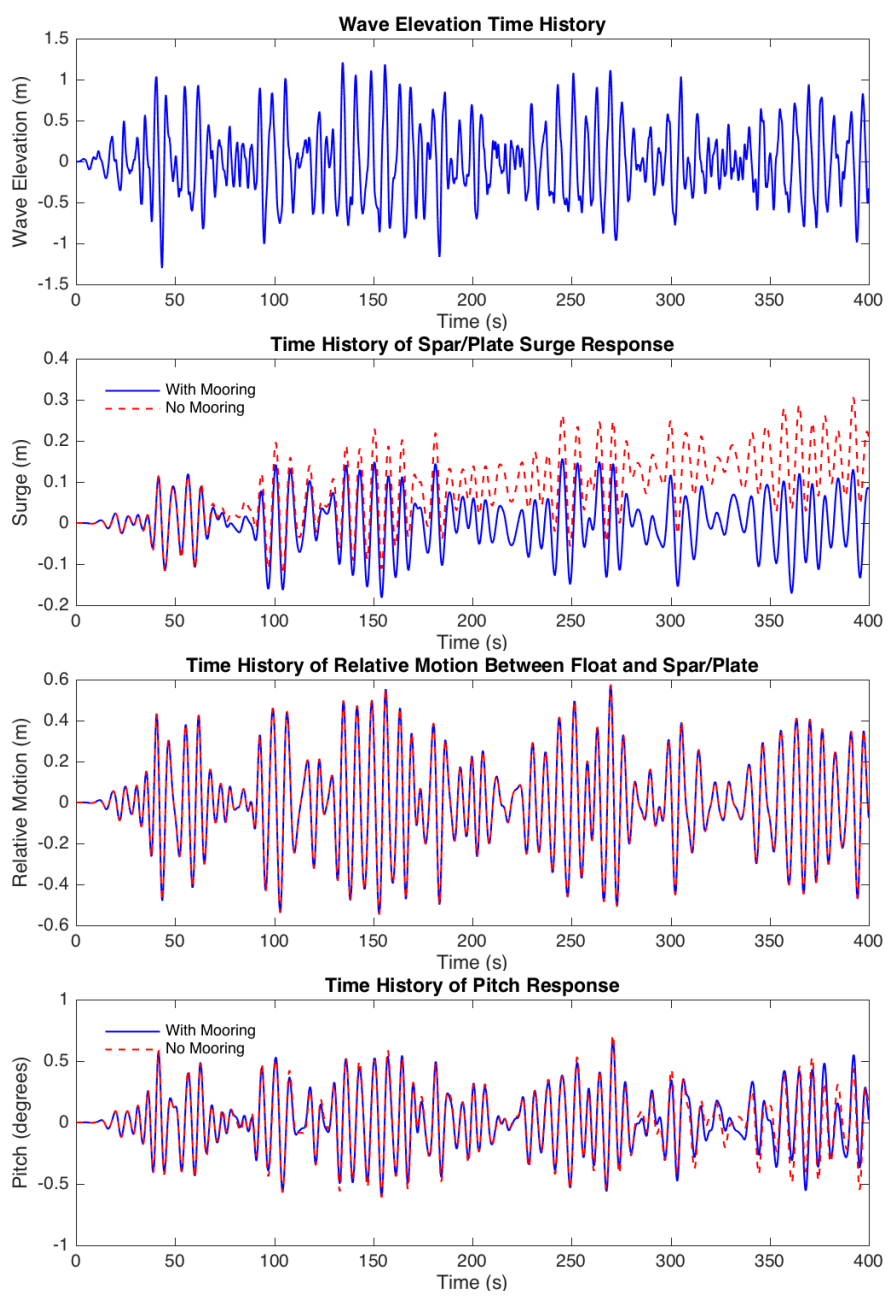

FIGURE 16. TIME HISTORY OF THE WAVE TRAIN AND DEVICE RESPONSE (WITH A RAMP TIME OF 40 S).

connection case was also analyzed. As shown in Fig. 16, the three-point mooring configuration provided additional restoring forces in surge to keep the device in position (what it was designed for), and had little influence on the device relative motion, which corresponded to its power output.

\section{CONCLUSIONS}

WEC-Sim was coupled with MoorDyn to improve its ability to model the mooring dynamics of WEC designs. The coupled numerical method was applied to simulate a FPS buoy and a twobody floating point absorber WEC device, in which both were chain-connected using the three-point catenary mooring system. The main purpose was to validate the mooring model implementation. The verification and validation study was carried out by comparing the WEC-Sim/MoorDyn simulation results to those predicted from OrcaFlex and measured from a model test.

Overall, the numerical simulation results compare well with those from the wave tank test. The shift of mean mooring force between the simulation results and those from the wave tank test was most likely caused by the imbalance of mooring connection. Both OrcaFlex and WEC-Sim/MoorDyn predicted similar results. In the regular wave study, the highest mean mooring lines fairlead tensions varied by $0.89 \%$ and the highest standard deviation varied by $9.8 \%$. In the irregular wave study, the highest mean mooring lines fairlead tensions varied by $0.44 \%$ (slightly lower than for the regular waves), and the highest standard deviation varied by $25 \%$, which seems high; however, the actual numbers of 0.008 and 0.006 are actually close and only off by 0.002 . A probable explanation for these differences is the number of members used to model the mooring system between OrcaFlex (12 members) and WEC-Sim (15 members). In addition, the solutions are expected to be close but not identical as the numerical implementation is different between OrcaFlex and WEC-Sim.

The WEC-Sim/MoorDyn model was also applied to model a two-body floating point absorber in the study. The dynamic response of the system was analyzed with and without a mooring connection to demonstrate the use of mooring for providing additional restoring forces in surge to keep the device in position. Future work will include applying WEC-Sim/MoorDyn to simulate systems with more complicated mooring configurations, and conducting further investigation of extreme condition modeling and fatigue analysis. The studies can be useful for gaining a better understanding of the required mooring configuration and its efficiency for various types of WEC designs.

\section{ACKNOWLEDGMENT}

This work was supported by the U.S. Department of Energy under Contract No. DE-AC36-08GO28308 with the National Renewable Energy Laboratory. Funding for the work was provided by the DOE Office of Energy Efficiency and Renewable Energy, Wind and Water Power Technologies Office.

\section{REFERENCES}

[1] Yang, S.-H., Ringsberg, J. W., and Johnson, E., 2014. "Analysis of Mooring Lines for Wave Energy Converters: A Comparison of De-Coupled and Coupled Simulation Procedures," In 33rd International Conference on Ocean, Offshore and Arctic Engineering, OMAE, San Francisco, CA, United States.

[2] Yu, Y.-H., Lawson, M., Ruehl, K., and Michelen, C., 2014. "Development and Demonstration of the WEC-Sim Wave Energy Converter Simulation Tool," In 2nd Marine Energy Technology Symposium, Seattle, WA, United States.

[3] Ruehl, K., Michelen, C., Kanner, S., Lawson, M., and Yu, Y.-H., 2014. "Preliminary Verification and Validation of WEC-Sim, an Open Source Wave Energy Converter Design Tool,' In 33rd International Conference on Ocean, Offshore and Arctic Engineering, OMAE, San Francisco, CA, United States.

[4] Hall, M., 2015. MoorDyn Users Guide.

[5] Hall, M., and Goupee, A., 2015. "Validation of a lumpedmass mooring line model with DeepCwind semisub- 
mersible model test data," Ocean Engineering, 104, pp. 590-603.

[6] Bosma, B., Sheng, W., and Thiebaut, F., 2014. "Performance Assessment of a Floating Power System for the Galway Bay Wave Energy Test Site," In International Conference on Ocean Energy, ICOE, Halifax, Nova Scotia, Canada.

[7] Orcina, 2011. OrcaFlex Manual.

[8] Cummins, W., 1962. The Impulse Response Function and Ship Motions, David Taylor Model Dasin (DTNSRDC).

[9] Lee, C., and Newman, J., 2015. WAMIT User Manual Version 7.1.
[10] Vissio, G., Passione, B., Hall, M., and Raffero, M., 2015. "Expanding ISWEC Modelling with a Lumped-Mass Mooring Line Model," In 11th European Wave and Tidal Energy Conference, EWTEC, Nantes, France.

[11] Neary, V. S., Previsic, M., Jepsen, R. A., Lawson, M. J., Yu, Y.-H., Copping, A. E., Fontaine, A. A., Hallett, K. C., and Murray, D. K., 2014. Methodology for Design and Economic Analysis of Marine Energy Conversion (MEC) Technologies, Sandia National Laboratories, Albuquerque, NM. 